\title{
CulturA : Discusión Acerca de su Vigencia en la Actualidad
}

\author{
Por: Tulia Almanza Loaiza* y María del Carmen \\ Docal**
}

Resumen

Actualmente se dispone de una gran variedad de teorías sobre la cultura que provienen de distintas disciplinas. En este texto se discutirán algunos conceptos desde la perspectiva de algunas teorías de la antropología cultural y por otro, desde algunas conceptualizaciones de la filosofía de la cultura. La discusión retoma las propuestas de la antropología estructural y del particularismo histórico, las cuales traspasaron las teorías evolucionistas para explicar la conformación social y cultural como una totalidad, que pueden relacionar la estructura de parentesco y el orden social con las formas simbólicas y las creencias. Esta aproximación permite vincular la organización de los grupos sociales con las formas de participación política, con el ánimo de comprender y discutir las culturas marginales y la variedad de las llamadas subculturas urbanas, que reclaman hoy sus derechos ante el Estado democrático de derecho, a través de la búsqueda de reconocimiento. Como avance de esta discusión en torno a la cultura en el marco del multiculturalismo, se intenta mostrar que la organización social, el parentesco y su relación con la tierra son categorías de la antropología cultural, que aún tienen vigencia para comprender la configuración de los grupos sociales y culturales del país, especialmente los grupos mestizos, ya que estos se han presentado vinculados a la tenencia y explotación de la tierra y, por esa vía, se han configurado también grupos políticos e, incluso, partidos políticos de gran incidencia en la vida de la nación.

\section{Palabras Claves}

Antropología cultural, filosofía de la cultura, organización social,

\section{Perfiles}

* Tulia Almanza Loaiza es Docente de la Facultad de Ciencias Humanas y Sociales de la Corporación Universitaria Minuto de Dios. Antropóloga, Magíster en Filosofía de la Universidad Nacional.

** María del Carmen Docal es Docente de la Facultad de Ciencias Humanas y Sociales de la Corporación Universitaria Minuto de Dios. Trabajadora Social. Magíster en Estudios Políticos de la Pontificia Universidad Javeriana.

\section{CULTURE: DISCUSSION ABOUTITS CURRENT VALIDITY}

\begin{abstract}
Currently there are a great variety of theories over culture that comes from different disciplines. In this paper the discussion is based around two perspectives: Firstly from cultural anthropological theories and secondly from conceptualizations of cultural philosophy. The discussion is based on structural anthropology and of the historical particularization which transmits the evolutionist theories to explain the social and cultural conformation as a whole. That they can relate the structure of familiarity and social order to the symbolic forms and believes. This approximation allows the social organization groups to unite with political participative ways and with the aim of understanding and discussing cultural marginalities and the variety of the so called urban subcultures that today demand their rights before a democratic state; achieved through searching for proper identification.
\end{abstract}

\section{Key Words}

Cultural anthropology, cultural philosophy, social organization, familiarity, land possession, migration, mestizo community

Recibido, 25 de mayo de 2007; aprobado, 15 de junio de 2007 


\section{LA CULTURA EN LA FILOSOFÍA}

El término cultura ha sido utilizado en los últimos tiempos de manera muy profusa, pero eso no significa que se cuente con conceptos claros. Hoy se hallan una gran variedad de teorías acerca de la cultura, que provienen de distintas disciplinas como la antropología, la sociología, la psicología y ramas disciplinarias como la filosofía de la cultura. Tal amplitud de teorías y de conceptos, genera significados muy diversos, a veces contradictorios, a veces muy difusos o confusos'. En este artículo se discutirán algunos conceptos desde la perspectiva de algunas teorías de la antropología cultural, así como desde algunas conceptualizaciones de la filosofía de la cultura. Se retoman propuestas de la antropología estructural y del particularismo histórico que traspasaron las primeras teorías evolucionistas para explicar la conformación social y cultural como una totalidad, que podían relacionar la estructura de parentesco y el orden social con las formas simbólicas y las creencias. Esta aproximación, permite vincular la organización de los grupos sociales con las formas de participación política con el ánimo de comprender y discutir las culturas marginales y la variedad de las llamadas subculturas urbanas, que reclaman hoy sus derechos ante el Estado democrático de derecho, a través de la búsqueda de reconocimiento.

En la antigüedad, se encuentran pocas referencias al término. Los romanos lo utilizaban para designar el cultivo de las cosas, así como el cultivo de las capacidades del hombre. Cicerón se refiere a la cultura para designar la formación o educación del hombre, como lo afirma Sobrevilla: "la cultura del alma es la filosofía, que lleva al hombre a conseguir su humanitas, es decir su condición humana." ${ }^{2}$
En la Edad Media la cultura como formación se diluye para ser entendida como $<<$ moderatio $>>0<$ perfectio $>>$, en el sentido, que el hombre tenía que buscar y seguir un camino de perfectibilidad de su ser. Más tarde el humanista español Juan Vives recupera el vocablo en sus obras sobre la enseñanza, mientras Francis Bacon se refiere a la cultura como parte de la ética, la $<<$ cultura animi $>>$, la cual buscaba los medios para someter o formar la voluntad del hombre a la moral.

David Sobrerilla, coincide con otros autores en que es en la modernidad cuando se impulsa el uso del término y cuando desarrollan estudios propiamente culturales. El jurista alemán Samuel Pufendorf, diferenció el sentido objetivo, que designaba los conocimientos y las actividades que permiten superar el estado de naturaleza; del sentido subjetivo, que se refiere al cuidado que todo hombre debe tener para superar ese estado de naturaleza, mediante el cual, puede vivir en sociedad.

Quienes formularon con mayor precisión el concepto de cultura fueron los iluministas, para designar todas las creaciones y realizaciones del hombre. Montesquieu y Turgot insistieron en que no se trataba solamente de la formación del hombre, sino, que las cosas objetivas producidas por el conjunto de los hombres, están sometidas a leyes objetivas que le son propias. Posteriormente, Condorcet y Hegel seguirán este camino.

Sobrevilla destaca la figura de Herder (17441803) en el desarrollo del concepto de cultura. En obras tan importantes como ldeas para una filosofía de la historia de la humanidad y También una filosofía de la historia de la humanidad, (1774), Herder se refirió a la cultura en el sentido subjetivo, pero también en un sentido antropológico más amplio, como la cultura de un pueblo.

1 Esta perspectiva clásica de la antropología cultural cobra vigencia en una mirada hacia la realidad de los grupos sociales del país muchos de los cuales viven en zonas rurales o han migrado hacia las ciudades manteniendo tradiciones de distinto tipo desde creencias religiosas hasta formas de parentesco. Las diversas formas de mestizaje e hibridación que hoy se encuentran en grupos y clases sociales mantienen aún referentes simbólicos regionales, apego a la provincia a grupos de parentesco o patronazgo aún cuando estos se encuentren fragmentados y en crisis. Estas presencias culturales contribuyen a la dificultad de conformación de ciudadanos libres que puedan insertarse en la vida civil y participen en la democracia de manera plena.

2 Sobrevilla, D. "Idea e Historia de la Filosofía de la Cultura", en: Filosofía de la Cultura. Enciclopedia Iberoamericana de Filosofía. Editorial Trotta, $1^{\circ}$ Edición, Madrid, 1998, pag. 16 
"En el primer sentido, la cultura significaba para él el despertar del hombre espiritual en el hombre físico y equivalía a una segunda génesis del hombre; en el sentido antropológico la cultura de un pueblo se entendía como el <florecimiento de su existencia, con la que se manifiesta de manera grata pero frágil>; y en el sentido objetivo pensaba en la cultura como en las consecuciones permanentes del hombre, y en la tradición que se forma por el tránsito de los pueblos y que tiene como finalidad la realización de la humanidad en su conjunto. ${ }^{\prime \prime 3}$

Son estas fuentes las que alimentan también el surgimiento de la antropología cultural; además de Herder, el historiador suizo Jacob Burckhardt, se constituye en el fundador de la historia cultural, al sostener que la cultura es una de las tres fuerzas más importantes que determinan la historia, junto al Estado y a la religión. La cultura la consideraba como la suma de las creaciones humanas que toman forma en la sociedad, pero no reivindican ninguna validez universal.

Desde 1789 se abre una brecha en la historia de occidente; la Revolución Francesa genera movimientos sociales que no logran ser explicados por la filosofía social o la filosofía del derecho. Es la filosofía positiva de Comte la que procura desarrollar una ciencia nueva, que explique los recientes fenómenos como la pérdida de orden antiguo y el progreso científico y económico que empujaban. La ciencia positiva de Comte pretenderá superar la crisis conociendo las leyes de la acción. Si la física y la química podían dominar las fuerzas de la naturaleza, entonces las preguntas por el dominio de las fuerzas sociales se volverán cada vez más apremiantes. Las palabras de Kluckhon se asemejan mucho a las de Comte, en el sentido de buscar el progreso de la humanidad a partir del desarrollo tecnológico, pero guardando el orden. ¿̇Cómo lograr salir de las crisis creadas por la industrialización? Las teorías sociales nacientes, desde la sociología hasta la antropología y la historia, apuntaban a la creciente racionalización de la sociedad industrializada, de las sociedades urbanas donde la razón prevaleció sobre la tradición y la aleatoriedad. Dice al respecto Roger Bastide:

"Tiempo después Tönnies advertía que en el pasaje de las <comunidades> a las $<$ sociedades > -característico de nuestra época, con la urbanización y la industrialización- se daba también un pasaje de lo afectivo a lo racional. Pero es Max Weber quien mejor ha expuesto este movimiento hacia la racionalización de la acción: en la política, la autoridad burocrática sustituye a la autoridad carismática o a la autoridad tradicional; en el derecho, los derechos consuetudinarios dan paso al derecho racional; la secularización triunfa en materia de religión, y la planificación en el campo de la economía. El antropólogo quedó atrapado en esta corriente histórica." ${ }^{\prime 4}$

Se trataba de construir una ciencia que pudiese dominar las fuerzas sociales a partir de la razón, lo cual significó enfrentar un conjunto de problemas dentro de los cuales se resaltan dos: en primer lugar, distinguir el medio social del físico, debido a que las sociedades tradicionales presentan resistencia ante la racionalización que la industrialización ejerce sobre la naturaleza, planificando la economía, lo cual se evidencia en el hecho de que los hombres en esta nueva era pueden luchar contra los determinismos de la naturaleza; por otro lado; por otro, la dirección que se le debían dar a las fuerzas sociales. El antropólogo Levy Brühl decía, a este propósito, que "no existe una ciencia de los fines, sólo una ciencia de los medios", aunque muchos intentaron desarrollarla para los fines, como es el caso de los primeros antropólogos norteamericanos que sólo plantearon el problema de los fines desde la moral, pero, ante lo que surgió el planteamiento de una moral universal, como lo hace entonces Bastide:

"Deberíamos preguntarnos si, en realidad, esos fines que se asignan a la acción humana en el control sobre las fuerzas sociales no serán los fines de una cultura -la nuestra- que pretendemos oponer a culturas distintas. ${ }^{15}$

3 lbid. pag. 18

4 Bastide, R. Antropología Aplicada, Amorrotu Editores, Buenos Aires, $1^{\circ}$ Edición , 1977, pag. 9

5 lbid. pag. 10 
En la realidad, se encontró una pluralidad de grupos, los estudios de la antropología cultural mostraron una gran variedad de fines y de valores, una diversidad de culturas, que en el contacto con las europeas generaron dinámicas que las transformaron. Mientras unas lucharon por mantener sus tradiciones y su existencia, otras se asimilaron a las dominantes o sufrieron sincretismos ante el avance de la industrialización y la economía de mercado.

\section{ANTROPOLOGÍA CULTURAL Y ORGANIZACIÓN SOCIAL}

El surgimiento de la antropología cultural se entreteje con las discusiones del evolucionismo, en la pretensión universalista de ubicar una cultura más avanzada, más progresista sobre otros pueblos poseedores de tradiciones atrasadas 0 deficientes. En la época de la conquista y, posteriormente, durante la extensa colonia, los pueblos europeos elaboraron estrategias tendientes a modificar la cultura de los pueblos colonizados, como transformación de los comportamientos, la reorganización de las estructuras sociales, el obligar a los habitantes a asumir nuevas creencias religiosas, etc. A este fenómeno se le llama recientemente aculturación controlada y, para Bastide, es un fenómeno que data desde el comienzo de las relaciones interétnicas. "El grupo misionero pretendía arrancar a las tinieblas del paganismo las almas de los indígenas, para hacerlos elevarse a la fe cristiana." ${ }^{16}$

Pero fue hasta la segunda mitad del siglo XIX cuando las primeras teorías antropológicas apoyadas en el evolucionismo defendieron y en especial Morgan, la tesis, según la cual, todos los pueblos pasan por los mismos estadios de desarrollo: salvajismo, barbarie y civilización; entonces se hizo necesario explicar, si esta premisa era verdadera, ¿̇cómo podría explicarse que todos los pueblos no avanzaran al mismo ritmo o se hubieran detenido?

Los pueblos más avanzados pueden ayudar a los más retrasados a ingresar en la senda de la civilización, e incluso, la etnología historicista afirmó que era posible pasar al estado positivo o científico sin pasar por la barbarie o por el estado fetichista. En todo caso, se planteó como problema central el descubrir las causas del estancamiento de algunas poblaciones que no les permitía pasar a los siguientes estadios. Autores como R. Allier en sus libros como Le non civilisé ef nous (1928), buscaron causas morales para explicar el retraso de los pueblos, ya que la civilización sólo es posible bajo el control de las funciones superiores, como la Razón y la Voluntad, sobre las funciones inferiores, el instinto y la afectividad.

"En determinado momento de su evolución el hombre se encontró ante una encrucijada; algunos pueblos optaron por el esfuerzo (aquellos que fueron tocados por el cristianismo) y otros eligieron el erotismo irrestricto (relacionado con el paganismo). El cultivo de la sensualidad sería, pues, responsable de los estancamientos en el desarrollo, el debilitamiento de la voluntad creadora y la caída en el magismo que por excelencia representa el antiprogreso. ${ }^{\prime 7}$

El evolucionismo no logró explicar la variedad de las culturas no europeas, como tampoco la oposición entre mente prelógica y mente lógica. En Estados Unidos, el antropólogo Franz Boas denunció la falsedad de esta idea, abriendo el camino hacia la antropología cultural, basado en la premisa de que no existen culturas superiores ni inferiores, sólo distintas. El gran error del evolucionismo consistió en juzgar a las distintas culturas a partir de un cerrado etnocentrismo. En las últimas décadas del siglo XIX, Boas recibió un influjo muy acentuado de Wilhelm Dilthey, desde donde rechazó al evolucionismo y al fisicalismo. Dice al respecto Marvin Harris:

6 Ibid. pag. 15

7 Allier, R. Le noncivilisé et nous, 1928, citado por Bastide, op. cit. 1977, pag. 17 
"Al insistir en la variedad de la historia, es obvio que Boas tomó posición contra los esquemas evolucionistas que incluían a toda la humanidad en una única fórmula de desarrollo. Mas en el contexto de su tiempo, el desprecio por la moda de los paralelismos universales de base puramente lógica estaba más que justificado. Esto no significa que Boas se erigiera conscientemente en defensor de la proposición de que en la historia no existen regularidades, sino que más bien era consciente de que el alcance se había sobreestimado groseramente. ${ }^{18}$

Boas sabía que las generalizaciones son tan importantes para la formulación de una teoría de la cultura, como las pruebas etnográficas particulares de distintos pueblos. Como había estudiado geografía, física y matemáticas en Berlín, su visión del mundo estaba muy influenciada por la ciencia natural y formal, pero sus primeros estudios entre los esquimales, le hicieron cambiar su posición y virar hacia una teoría cultural. Después de convivir largas temporadas con esta comunidad, tuvo que llegar a la conclusión que hacía lo que hacía y pensaba lo que pensaba a pesar y, no a causa, del medio físico. Para comprender una cultura, Boas insistía en la importancia de la perspectiva émica, es decir en la visión del sujeto observado y en su propia versión de la historia. Es decir, que el camino para la comprensión de la vida del otro pasaba por el estudio de la historia de cada individuo como, lo afirmaba también Dilthey.

"Debemos reconocer que en sus orígenes el particularismo histórico fue concebido como el auxiliar de una perspectiva histórica nomotética. Las culturas específicas tenían que ser estudiadas en su contexto histórico particular. Había que hacer esto no porque la búsqueda de uniformidades en la historia fuera útil, sino porque la única vía por la que podía apreciarse el alcance y la naturaleza de estas uniformidades era a través de un programa de investigación histórica inductiva. En otras palabras: la intención de Boas no era, como él mismo repitió en numerosas ocasiones, abandonar la investigación de las regularidades de la historia. No esperaba que el particularismo histórico reemplazara al método comparativo, sino que lo complementara y facilitara el descubrimiento de las leyes, que seguían constituyendo el objetivo último de la investigación antropológica. ${ }^{19}$

Se puede decir que el problema de la inducción planteado por Popper aparece aquí evidenciado, en el sentido en que cada cultura, tiene un valor único y por lo tanto no pueden sumarse al de otras culturas distintas. Entonces, la comprensión de una cultura particular no podía aportar a una ley general de la historia y de la cultura, posibilidad que, Boas consideró, pero se encontró con la gran dificultad de no contar con una teoría general que le permitiera conectar tantos datos y hechos particulares.

\section{Tribus y civilizaciones}

Marshall Sahlins considera que la división entre pueblos civilizados y primitivos sigue siendo válida, si se acepta un concepto histórico que no estudie los distintos estadios del progreso, sino, las diferencias en las fuerzas económicas y la presencia o no del Estado.

El paso del paleolítico al neolítico decidió el tránsito de los cazadores hacia la agricultura y, con ello, hacia la llamada cultura tribal. El cultivo del suelo y la consiguiente economía agraria permitieron a estos pueblos desarrollar una territorialidad estable, desplazando a pueblos recolectores y cazadores a zonas más inhóspitas; y en esas zonas desérticas o demasiado húmedas, o frías subsistió el paleolítico.

"Todo esto se produjo muy rápidamente, si se
considera desde la perspectiva total de la historia
humana. Los primeros agricultores de que hay
constancia arqueológica ocuparon bosques
montuosos y valles del Próximo Oriente desde
donde hombres del neolítico parecen haberse
desarrollado durante el período comprendido
entre 10.000 y 7.000 años a. de C. Hacia el 2000
antes de nuestra era hubo comunidades
neolíticas a lo largo de Eurasia, desde Irlanda
hasta Indonesia. En el Nuevo Mundo la
domesticación de los alimentos comenzó algo

8 Harris, M. El Desarrollo de la Teoría Antropológica, S. XXI Editores, Madrid, Primera Edición en Español, 1978, pag. 225.

9 Harris, M. op. cit. pag. 238 
más tarde que en el Antiguo: el producto principal del neolítico americano, el maíz, parece haber sido cultivado por vez primera hacia el 5000a, de C. en América Central. Tras un período de lenta gestación la cultura neolítica se extendió amplia y rápidamente; en tiempos de Jesucristo se hallaba distribuida desde Perú hasta el suroeste americano."

Sahlings sostiene que la economía agraria no necesariamente empujó el surgimiento del la cultura tribal, pues ésta pudo aparecer mucho antes en sociedades cazadoras complejas, como los kwakiutl, de Norteamérica y otras de México. Estas tribus cazadoras ya contaban con la presencia de clanes organizados de manera compleja y luego adoptaron tecnologías neolíticas que les permitieron transformar el ambiente al controlar el agua, acumular alimentos, construir asentamientos más estables, todo lo cual a su vez ayudó a mantener un orden social más estable. Las culturas tribales vivieron miles de años, colonizaron todos los ambientes del planeta y fueron la base de la civilización. Antes del siglo XVI la distribución de las culturas tribales ya había sido cercenada, reducida a la América septentrional al sur del Canadá hasta el Norte de México, al Caribe, la Amazonía, los valles interandinos, el centro de África, al sur del Sahara, al Asia interiory Siberia, el Asia suroriental y las islas de la cuenca del Pacífico. En esas mismas regiones se encuentra el mundo tribal de hoy que ha sido también el más estudiado por la antropología cultural.

El contraste más grande entre las culturas tribales y la civilizaciones es, según Thomas Hobbes, la guerra y la paz, y no porque las primeras vivan en un permanente estado bélico y las segundas lo hayan superado. Es más bien que la complejidad social de la civilización y su riqueza cultural ha desarrollado instituciones que permiten y hasta pueden garantizar la paz. Cuando faltan instituciones, las poblaciones tribales viven en estado de guerra, y ésta limita y conforma la riqueza cultural. Guerra no significa batalla, sino una predisposición o una inclinación a la guerra en la que la violencia puede ser usada por todos los miembros del grupo. No significa que se viva en medio de la violencia, pero no significa tampoco que ésta no se presente. El Estado es la diferencia entre la sociedad tribal y la sociedad civilizada, el cual significó una transformación cualitativa del sistema social. Se ha planteado que la diferencia se encuentra en la presencia de la escritura o de la economía de acumulación; pero pueblos iletrados, como los incas del Perú, desarrollaron un Estado Imperial muy avanzado y pueblos cazadores como los Zúlu en el Centro de África también lo hicieron."

Un Estado tiene un gobierno auténtico, soberano y legítimo que se separa del resto de la población, gracias a la fuerza que posee por encima de ella. El derecho a controlar la fuerza pasa a ser privativo del Estado y la autoridad no puede ser ejercida sino por delegación de ese poder central soberano; el dominio sobre la sociedad se encuentra dividido territorialmente y está sometido a su jurisdicción normativa.

De esta manera el Gobierno funciona como el sistema central de un organismo vivo y, así como regula la fuerza también, regula la vida social, mantiene las partes del orden económico, y demás segmentos culturales colaborando entre ellas para mantener la paz.

Hoy la antropología cultural ha aprendido mucho sobre los pueblos primitivos y las palabras de Hobbes, suenan un poco desactualizadas, pues esa $<<$ guerra de todos contra todos, a pesar de que nunca se ha producido $>>^{12}$, conduce a pensar que las sociedades tribales no pueden garantizar la seguridad y prosperidad de sus culturas más que por la amenaza permanente de la guerra. Sin embargo, los componentes de las sociedades tribales viven en comunidades sostenidas por formas de parentesco, en las cuales la normatividad es tan firme que puede sola mantener el orden. Un estudio detallado de las instituciones tribales, muestra que la anarquía primitiva es nada más que una apariencia. Pero eso no significa que no sea necesario reglamentar la guerra. Dice el autor:

10 Sahlins, M. Las Sociedades tribales, Primera Edición en español, 1972, Editorial Labor, Barcelona, pags. $12-13$

11 Cfr. Ibid. pas. 16-17

12 Hobbes, Leviatán, $1^{\circ}$ parte, cap. XIII, citado por Sahlins, op. cit. pag. 20 
"En realidad, no cabe la esperanza de sobrevivir a menos que se reglamente la guerra. Por eso tiene por un precepto de la razón que los hombres busquen la paz y, luego, que el juego de la razón no pueda garantizarse fuera del Estado (República - cosa pública). A lo que voy es a que el establecimiento de la paz es la sabiduría de las instituciones tribales. Además, por el hecho de que estas instituciones tribales deben soportar su carga política, a veces, son completamente distintas de las instituciones análogas de las civilizaciones." ${ }^{\prime \prime 3}$

Para entender las instituciones tribales es necesario volver sobre las teorías clásicas de la cultura y de la sociedad según las cuales, las culturas presentan tres componentes fundamentales: la tecnología, la organización social y la ideología. Con frecuencia se destaca a la tecnología o la llamada cultura material como la más importante ya que ésta es el producto de relaciones sociales de producción o formas económicas. Pero en sociedades tribales o sociedades atrasadas tecnológicamente, este esquema se desfigura, ya que la producción, las formas de gobierno, el orden social de parentesco y la ideología basada en el mito no están separados. Más bien, las formas económicas pueden ser bastante similares, como también la tecnología que varía en adaptaciones distintas de acuerdo al medio ambiente. En una organización de este tipo no hay tantas instituciones, pero la misma institución puede cumplir con muchas funciones. Un linaje se encarga de conservar y manejar el patrimonio de tierras y la distribución de sus productos tanto internamente como en fiestas rituales con otros grupos afines; cuando ofrece sacrificios a los antepasados aparece como una organización religiosa; cuando se presentan dificultades y conflictos los jefes del linaje actúan políticamente.

Así, la unidad constitutiva de la comunidad tribal es el hogar donde se van incluyendo a los demás, que constituyen el linaje hasta que un conjunto de ellos conforman una tribu. Los pequeños grupos se engranan con los demás para conformar familias extensas; las cuales se agrupan en linajes locales, éstos en comunidades aldeanas y luego en confederaciones regionales."Estas últimas constituyen una $<$ tribu $>$ o < pueblo $>$ distribuido en un amplio campo intertribal ${ }^{1{ }^{14}}$, con el cual se intercambian en alianzas matrimoniales y patrimoniales.

Las unidades mínimas de estos sistemas de parentesco se denominan segmentos de otras más amplias que las incluyen en linajes y éstos en sistemas aún más amplios, como bloques de una construcción social que puede ser más o menos jerárquica; pero la cohesión de estos segmentos no la mantiene una institución política que desde $<<$ arriba $>>$ tenga el poder para imponer una autoridad. Más bien la reciprocidad de intercambios económicos y de matrimonios, que busca un flujo de recursos, y de personas basadas en la confianza, la cual permite establecer alianzas, que son la garantía de la paz. Marcel Maus estudió estos sistemas de intercambio, que configuraron a muchas de las culturas ancestrales del mundo haciendo girar y complementar su vida económica y política con la reproducción de la vida social y mítica.

"En las sociedades que nos han precedido o que nos rodean, e incluso en las costumbres de moral popular, no se da término medio, o se confía o se desconfía completamente; se deponen las armas y se renuncia a la magia o se da todo, desde la hospitalidad fugaz hasta la entrega de hijas y bienes. En estados de este tipo, los hombres han renunciado a sí para entregarse a dar y devolver. ${ }^{\prime 15}$

Para Maus las sociedades arcaicas -incluye en su clasificación sociedades tribales e incluso Estados en gestación que aún no se constituyen en reinos y menos en imperios- logran estabilizar sus relaciones a través de intercambios de bienes y personas, en alianzas de parentesco, que han permitido satisfacer mutuos intereses $y$ defenderlos sin recurrir a las armas, o al menos, intentando evitar al máximo los encuentros bélicos.

13 Sahllins, M. op. cit. pag.21

14 Ibid. pag.30

15 Maus, M. "Ensayo sobre los Dones. Razón y Forma del Cambio en las Sociedades Primitivas", en: Sociología y

Antropología, Editorial Tecnos, $1^{\circ}$ Edición en Español, 1971, Reimpresión 1979, pag .261 
Más allá de la discusión moral que presenta Marcel Maus, es interesante la posibilidad de estudiar un fragmento de la cultura, el intercambio de sus bienes que se presenta como constante en muchas sociedades y épocas de la historia humana, como un fenómeno total donde se mezclan de manera compleja los elementos de la cultura.

"Este trabajo es un fragmento de un estudio más amplio. Desde hace años, me he interesado a la vez por el régimen del derecho contractual y por el sistema de prestaciones económicas entre las diversas secciones o subgrupos de que se componen las sociedades llamadas primitivas, así como las que podemos denominar como arcaicas. Hay una variedad enorme de ellos, muy complejos, donde todo queda mezclado, todo cuanto constituye la vida propiamente social de las sociedades que han precedido la nuestra incluida la protohistoria-."16

La categoría de tribu ha sido, entretanto, discutida y criticada profundamente. La etnología norteamericana comenzó a trabajar con la categoría de $<<$ área cultural $>>$ después de la primera guerra mundial, la cual permitió analizar e interpretar los datos culturales de las situaciones concretas de relaciones interculturales en términos espaciales e históricos.

Para las poblaciones suramericanas este concepto tuvo mucha importancia desde las compilaciones que realizó Julian Steward a través del "Smithsonian Institute", denominado Handbook of South American Indians (1946-48). ${ }^{17}$ La organización considerada en este texto incluía para Colombia tribus marginales, de las selvas tropicales, caribes y civilizaciones andinas, es decir, que distribuía a las culturas autóctonas en la geografía colombiana a partir de la distinción $<<$ tribu $>>$ y $<<$ civilización $>>$, pero fueron cuestionadas tanto en Norteamérica, como en el país a causa de las inconsistencias históricas y las nuevas realidades socioeconómicas, especialmente, porque los procesos de aculturación habían producido integración y mestizaje, como también desaparición de muchos grupos.

Antropólogos como Reichel-Dolmatoff (1959) y Virginia Gutierrez de Pineda 1975) propusieron otras categorías que combinaban el concepto de área cultural y de $\langle\langle$ grupo $\rangle\rangle$, que contemplan complejos culturales que no coinciden necesariamente con las regiones naturales sino que presentan rasgos similares de economía, religión, tipologías de parentesco, ritos ceremoniales, tradiciones médicas, etc.

\section{Campesinado y mestizaje}

Otro grupo socioeconómico y cultural de gran importancia en la historia humana, son los llamados campesinos que se diferencian de las sociedades primitivas, dado que estas controlan los medios de producción y su propia fuerza de trabajo, además de intercambiar productos y servicios con grupos equivalentes. Cuando aparecen los Estados y, con estos la civilización, los labradores tienen que transferir sus excedentes e, incluso su producción, a un grupo dominante, el cual se encarga de redistribuir esos remanentes de producción en los grupos no labradores, a cambio de servicios como salud y seguridad. ${ }^{18}$

"El campesino existe siempre en el seno de una sociedad más amplia. Por ello, el grado de esfuerzo que debe realizar para reemplazar sus medios de producción o para pagar el coste de sus ceremonias también se crea en función de las formas en que el trabajo está dividido en la sociedad a que tales campesinos pertenecen y depende así mismo de las normas que regulan esta división del trabajo."19

En el mundo actual se integran y coexisten, aunque no de la mejor manera, grupos primitivos y grupos campesinos en medio de una sociedad mayor, dentro de la cual los campesinos son los principales productores de la riqueza social

16 Ibid. pag. 157

17 Cfr. Correa, F. "Regionalización Socio cultural en Colombia". En: Revista Colombiana de Antropología, Vol. XXVII, años

1989-1990, Bogotá, Instituto Colombiano de Antropología, pags. 117-136

18 Crr. Wolf, E. Los Campesinos, Editorial Labor, Barcelona, 1971, pags. 12-16

19 lbid. pag. 17 
primaria. Afirma Eric Wolf que existen vastas regiones del mundo, en las cuales los campesinos cultivan la tierra de manera tradicional, constituyendo la mayoría de la población y facilitando, también, fondos de renta que aseguran beneficios económicos y estabilidad a la estructura social.

Con la revolución industrial, las máquinas se introdujeron al campo desplazando las formas tradicionales de producción y convirtiendo las relaciones de parentesco y de patronazgo en relaciones obreras de producción.

En Colombia, la población campesina proviene del mestizaje. El espacio geográfico del país fue ocupado por dos tipos de economía dentro del desarrollo histórico que, fue común al continente a partir de la colonización española. En las costas Atlántica y Pacífica se instituyó, desde la época colonial, la explotación de la tierra basada en la mano de obra esclava, hasta entrado el siglo XIX. Estas explotaciones se convirtieron luego en haciendas latifundistas y los esclavos pasaron a ser aparceros cuando la esclavitud ya no podía sostenerse, tal y como sucedió en el sur de Estados Unidos, el Caribe y el Brasil. La esclavitud no se reproduce a sí misma, sino que se renueva con la compra de nuevos esclavos; cuando se disolvió, la reconstitución de esta población fue posible alrededor de la mujer que, con base en la $<<$ aparcería $>>$ como vínculo con la tierra, se estabilizaron unas relaciones de parentesco siendo ella la cabeza de la familia que fue acumulando un poder que creció a medida que se observaba su permanencia. ${ }^{20}$

La economía terrateniente organizada alrededor de la hacienda, ocupó las tierras más fértiles y accesibles que mantenía a la mayoría de la población mestiza como arrendatarios a través de las deudas y el control político y religioso. De acuerdo con Salomón Kalmanovitz:

"Este campesinado estaba sometido a periódicas faenas gratuitas (la obligación), rentas en productos como los 'terrajes', rentas que combinaban un salario atrofiado y una coerción extraeconómica, donde primaba la segunda, como el 'concierto' o la 'agregatura' y finalmente los 'colonatos' de las inmensas haciendas ganaderas de las tierras bajas". ${ }^{21}$

En segundo lugar, se presentó también un campesinado subdividido en sectores, de distinto desarrollo técnico, que ocupaban -y en algunas zonas aún ocupan- tierras pobres de vertiente andina y también algunas de buena calidad que, antiguamente, fueron resguardos indígenas. En el oriente santandereano y en el occidente de Antioquia, se desarrolló una economía campesina y artesanal compuesta por migrantes españoles pobres y población mestiza. Las tierras que ocuparon eran de regular calidad y tuvieron que enfrentar, en muchas ocasiones, las pretensiones monopolizadoras de los terratenientes. En estas zonas, el campesinado minifundista desarrolló una familia patriarcal importada de España muy unida a la religión católica. Este tipo de familia se constituyó en una necesidad para los parceleros y pequeños propietarios:

"En Antioquia la parcela genera rasgos en cierto modo contrapuestos a los que produjo el latifundio en la costa; por ejemplo el aislamiento originario; ya les había dicho que el antioqueño es de carácter reservado y tímido: Pero también la parcela es una contradicción, por lo siguiente: no tiene más relaciones con sus vecinos que relaciones de compadrazgo y de linderos. (...) la cultura de las vertientes es una cultura cuyo principal rasgo histórico es que fue fundada por colonos libres y no bajo la forma de servidumbre ni de la esclavitud." 22

En estas regiones de vertiente, se inició a finales del siglo XVIII una colonización interna que avanzó por la Cordillera Central, pasando por el río Cauca y, hacia el norte, a través de las sabanas del Sinú. Esta colonización se llevó casi un siglo en

20 Zuleta, E. "Tres culturas familiares en Colombia", E. Revista Número, Edición 30 Septiembre-Octubre-Noviembre de2001, pag.75

21 Kalmanovitz, S. "Desarrollo capitalista en el campo colombiano"; en: Colombia Hoy, $2^{\circ}$ Edición Siglo XXI Editores, Bogotá, 1978, pag. 279

22 Zuleta, E. op. cit. Pags. 76-77 
que los colonos libraron una lucha contra las instituciones coloniales e, incluso, contra las republicanas en términos del cobro de rentas. La región continuó desarrollando las grandes haciendas, que también tenían importancia en el valle del Río Magdalena, la región del Gran Tolima y bajo Magdalena hacia el sector de la depresión Momposina. Estas haciendas mantuvieron la aparcería, aún cuando el avance técnico se iba introduciendo en la agricultura y la ganadería. Así se desarrollaron las fuerzas productivas de gran importancia para la expansión cafetera a finales del siglo XIX, que transformaron todas las relaciones económicas y culturales del país.

Afirma Kalmanovitz que la inserción de Colombia al mercado mundial y al desarrollo del capital, se presentó al tiempo con la expansión del cultivo del café, la construcción de una infraestructura vial, la transformación de muchos campesinos aparceros o minifundistas en asalariados de las grandes haciendas cafeteras, dedicados a la recolección de las cosechas. El desarrollo del mercado interno en estas regiones se impulsó gracias a esta economía agraria que liberó a muchos campesinos de las agregaturas o aparcerías. Desde 1880, las grandes haciendas de Santander, Antioquia, Tolima y Cundinamarca se habían dedicado a este cultivo de exportación, pero la mano de obra en muchas de ellas se mantenía en formas de sujeción, lo cual propició muchos conflictos de tipo político, que tendrían consecuencias en las primeras décadas del siglo $X X$. Los terratenientes utilizaban una contabilidad particular que resultaba, por lo general, en deudas con saldo en rojo para los trabajadores, situación que impedía dejar la hacienda bajo pena de cárcel o en el cepo.

"Los arrendatarios, según correspondencia de un terrateniente con su mayordomo que recopiló Malcom Deas, eran importados de las haciendas más tradicionales de la Sabana de Bogotá y de Boyacá, pues al parecer, la mano de obra de las tierras medias donde se puede mejor cultivar el café, se resistía a entrar en este tipo de 'conciertos'. Esta dificultad para conseguir y mantener a la fuerza a la mano de obra en las haciendas era obviamente una traba considerable para expandir rápidamente la producción para la exportación, más aún cuando el período vegetativo entre la siembra del cafeto y su entrada en la producción era de 4 años. ${ }^{\prime 23}$

El resto de la economía campesina, a diferencia de la colonización antioqueña, estaba conformada por indígenas y por mestizos, quienes también avanzaban en la colonización de montañas, por la presión que ejercían los grandes terratenientes. De esta manera, surgió un refugio para los campesinos que se rehusaban a la servidumbre de las haciendas aunque sólo se verían completamente libres cuando se establecían lejos de su área de influencia. Si este no era el caso, los terratenientes los utilizaban como jornaleros ocasionales, a veces de manera forzosa, como la "matrícula" que se presentaba en amplias zonas de la Costa Atlántica; también fueron forzados a trabajar en obras públicas. ${ }^{24}$

Las condiciones de estos campesinos parcelarios eran muy precarias, pues las tierras que ocupaban eran fácilmente erosionables. Sus productos tenían poca salida a los mercados, razón por la cual producían para la autosubsistencia, aunque el acceso a las ciudades fue mejorando con el desarrollo de la red vial nacional, que se fue completando hacia 1940.

En el sur del país la hacienda se mantuvo tranquila en un circuito de "autosuficiencia" gracias a la explotación de la mano de obra indígena. Los propietarios de estas grandes haciendas contaban con núcleos numerosos de "terrazgueros", que también empezaron a movilizarse contra la usurpación de sus resguardos hacia los años 20. Las haciendas del Valle del Cauca contaban con agregados mestizos y con descendientes de esclavos, quienes producían panela y azúcar y cuidaban el ganado.

$23 \mathrm{lbid}$. pag. 281

24 Esas formas de colonización se mantuvieron a lo largo del s.XX para ampliar la frontera agrícola. En las últimas décadas esas nuevas tierras colonizadas en los Llanos Orientales, el sur del Cauca, el Caquetá y el Putumayo se dedicaron a los cultivos ilícitos. 
Entre 1900 y 1940 la producción azucarera fue empujada hacia la industrialización que rápidamente transformó la economía de la región, el poblamiento y la cultura. ${ }^{25}$

\section{La desestabilización de la hacienda}

El gran auge de las exportaciones cafeteras, hacia 1929, multiplicaron las divisas del país, permitiendo la acumulación de capital para expandir y consolidar el capitalismo y la industrialización a nivel nacional. Esta expansión trajo consigo una gran demanda de mano de obra libre para recoger las cosechas y construir la infraestructura de vías, comercio y urbanización.

Los campesinos parceleros se integraron masivamente al mercado laboral agrario y también, a las industrias nacientes de manufacturas elementales, como la metalmecánica, la textil, el calzado, los cigarrillos y los electrodomésticos, en ciudades como Bogotá, Medellín, Cali y Barranquilla. Sin embargo, los terratenientes protestaban por este aumento de las actividades mercantiles e industriales, intentando prohibir la salida de sus arrendatarios de las haciendas. La SAC, Sociedad de Agricultores de Colombia, se quejaba en 1928 de los altos salarios ofrecidos en la industria, situación que aflojaba la disciplina de trabajo, "(...) lo cual debía ser especialmente cierto para los peones que prestaban rentas de trabajo en las haciendas más atrasadas y exigían un estatuto de ahorro forzoso por medio de un diferimiento de los salarios a los trabajadores. ${ }^{26}$

La situación se complicó cuando se inició el movimiento campesino y obrero en las haciendas cafeteras, especialmente en Tolima y en Cundinamarca; el cual pedía la extinción de las obligaciones laborares gratuitas y el equilibrio de los salarios rurales con los urbanos. El movimiento, tomó mucha fuerza obligando a los dueños de las tierras a transferir en propiedad las parcelas a los arrendatarios. Sin embargo, este conflicto de tierras se extendió hacia un problema político que terminó con la expulsión de los predios de la mayor parte de los arrendatarios.

Este conflicto político se evidenció, una vez el partido liberal accedió al poder en la década del 30. Las reformas jurídicas que se hicieron en 1936 expresaron este problema en la Ley 200 promulgada por Alfonso López Pumarejo, la cual pretendía resolver las "agregaturas", dando paso a la posibilidad de que un lote adjuntado a la hacienda pasara a ser propiedad del campesino, si demostraba adecuaciones y mejoras en 10 años. Estas consideraciones legales nunca se reglamentaron debidamente, especialmente, por la reacción contraria que presentaron los terratenientes, representados en el Partido Conservador. Sólo 25 años después, se reglamentó una nueva ley que de nuevo intentó resolver el problema campesino, a través de la Ley de Reforma Agraria en 1961.

De todas maneras, el capitalismo y la industrialización ya se habían disparado en el país. En un período relativamente corto de 1938 1973 la población rural pasó del $70.1 \%$ al 34,5\%. Dice el autor:

"El edificio social basado en la hacienda empieza a resquebrajarse con el movimiento campesino de los años 20, el cual lucha contra las relaciones serviles y por el pago de salarios, lo mismo que cuestiona el derecho de propiedad sin delimitar de los terratenientes sobre los supuestos baldíos de la nación. Esas fisuras se amplían durante la etapa de las reformas por arriba que desarrollaron los liberales y se profundizaron aún más con la 'violencia', guerra civil entre 1947-57, que desató la reacción contra el movimiento democrático." ${ }^{127}$

Después de 1936, la acumulación capitalista aceleró la diferenciación de la economía campesina y agraria, expandiendo y aumentando el número de consumidores, de la misma manera que lo hizo la población urbana, nucha de la cual se encontraba desempleada, lo cual condujo a

25 Cfr. Ibid. pags. 282-283

26 Ibid. pag. 285

27 Ibid. pag. 275 
que en las ciudades se reprodujera una economía doméstica. En este período de 1938-75 el desarrollo agrario del capitalismo en el campo fue más rápido que el desarrollo industrial: la agricultura se desarrolló al 12\% anval de forma independiente.

Kalmanovitz señala que este desarrollo acelerado en productos agrícolas como el café, el azúcar y luego el algodón, la soja y el arroz, se debió a que ganó la vía terrateniente en el desarrollo del agro y no la vía democrática, frenando así los intentos de reforma agraria de 1936 y de 1961. "Las relaciones sociales de producción capitalista avanzaron en razón inversa al debilitamiento de las relaciones de servidumbre características de la hacienda y la pérdida de importancia del trabajo familiar de la pequeña producción parcelaria y artesanal, aunque era cierto que ese proceso era profundamente desigual y contradictorio. ${ }^{\prime 28}$

\section{COMUNIDADES Y CIUDADANOS}

Después de esta breve revisión sobre la situación cultural y social del país, en la que se sostiene que una visión clásica aún tiene vigencia en algunos ámbitos de la sociedad, especialmente en la población campesina mestiza, que luego migro hacia las ciudades, cuando la estructura de las grandes haciendas se fue transformando. Es importante pasar a considerar el papel que estos grupos culturales y económicos, como indígenas y campesinos, así como pobladores marginales de las ciudades, tienen y han tenido en la conformación de la ciudadanía y la sociedad civil.

Wolf afirma que en las sociedades complejas actuales se mantienen y reproducen estructuras paralelas y suplementarias en los márgenes de la sociedad mayor; estructuras de parentesco ampliadas, círculos de amistades y de patronazgo propios del campesinado antiguo, que se trasladan a las ciudades de manera marginal. En América Latina, en el Mediterráneo europeo, en el centro de África, en el sureste asiático, prevalecen estas $<<$ estructuras no institucionales $>>$ que se superponen o traslapan en el sistema social moderno. ${ }^{29}$

Maria Teresa Uribe plantea que en el país, la ciudadanía mestiza ha predominado en la vida política, pues la presencia de rasgos comunitarios ha sido mayor que el desarrollo de la ciudadanía individual. La historia del país, desde la colonización española y la vida republicana, después de la independencia, ha pasado por grandes tensiones entre las comunidades mestizas, que se desarrollaron en procesos de aculturación e interculturalidad en el campo y una esfera pública regida por principios liberales modernos.

La autora, sostiene en su trabajo de investigación ${ }^{30}$ que la consolidación de los derechos civiles en el país presentan un déficit constante como resultado de un contrapunto entre comunidades y ciudadanos, dado que la ciudadanía liberal individual no ha podido consolidarse y, más bien, se ha establecido un orden político resultante de la amalgama de ideales liberales con comunidades locales, regionales y étnicas. Así, se han consolidado en el país las llamadas $<<$ comunidades mestizas $>>$ que han sido un componente fundamental en la trama política colombiana.

La defensa de esta tesis parte de dos argumentos: a.-La historia de los derechos en Colombia se ha desarrollado en el marco de la desigualdad que ha favorecido al orden colectivo frente a un déficit crónico de los derechos civiles y políticos. b.- La ciudadanía no se ha consolidado porque el orden político resultante de las amalgamas locales, regionales y culturales, condujeron al arraigo de ciudadanías mestizas.

28 lbid. pag. 276

29 Wolf, E. "Relaciones de parentesco, de amistad y de patronazgo en las sociedades complejas". En: Antropología Social de las sociedades complejas. Alianza universidad, Madrid, $1^{\circ}$ Edición en español, 1980.

30 Uribe, Ma. T. "Comunidades, ciudadanos y derechos". En: Cortés Rodas, F. Monsalve, Solórzano, Editores. Multiculturalismo. Los derechos de las minorías Culturales. Res Pública. Instituto de Filosofía de la Universidad de Antioquia, D.M. Librero Editor Murcia, 1999, pags. 144-143 
El liberalismo del tipo 1, de acuerdo con la tipología de Taylor ${ }^{31}$, tuvo presencia y expresión en Colombia durante la época de los liberales radicales, entre 1853 y 1886, cuando intentaron desarrollar una sociedad basada en el individuo, la secularización de la vida política, constituyendo una nación basada en el contrato social, sin referencias históricas, ni tradiciones políticas, culturales o étnicas. La idea del ciudadano individual estuvo presente, desde 1811, en muchos debates públicos y en las tertulias de las élites ilustradas del país. Pero, en la práctica, en los textos constitucionales y en la realidad, el ciudadano se definió aún en el marco colonial del $<<$ vecinazgo $>>$; "así se denominaba a los habitantes de una villa o ciudad que tuviese una casa poblada, que contribuyese al sostenimiento económico del cabildo y de la comunidad y que fuese reconocido como persona de honor y de respeto. ${ }^{\prime \prime 2}$

Este ciudadano tenía, entonces, rasgos comunitarios que se enmarcaban en una concepción corporativa de lo social y la pertenencia a la villa o poblado. Coincide este argumento con las razones que expone Wolf, con respecto a la supervivencia de comunidades cerradas corporativas de campesinos, especialmente, cuando el Estado no puede intervenir en la administración de la riqueza, pero que impone a la comunidad rural obligaciones colectivas de impuestos y trabajos no remunerados. Así la comunidad crea mecanismos corporativos para administrar sus recursos naturales y sociales y mantener así una relación más o menos estable con el Estado. Estos grupos son cada vez más escasos en el mundo moderno, pero persisten cuando no pueden insertarse económicamente en el comercio o la industria. Pueden trasladar estas formas corporativas a las ciudades, cuando tienen que migrar del campo a la ciudad y, mantener su organización en los barrios o poblados aledaños a las ciudades.
En el país esta figura del ciudadano colectivo arraigado localmente ayudó a mantener la diferencia entre $<<$ familias distinguidas $>>0$ $<<$ notables $>>$ frente a las $<<$ gentes del común $>>$, dado que las primeras poseían por lo general haciendas $u$ otros bienes que garantizaban su prestancia en la región y que, como se ha señalado, hacían parte fundamental de la economía hasta las primeras décadas del siglo XX. Este ciudadano colectivo se oponía a la constitución del ciudadano moderno de carácter universalista, secular con tendencia a la abstracción, al conocimiento científico, a las decisiones individuales.

"Si el liberalismo clásico no tuvo mayores antecedentes en el constitucionalismo republicano y en la vida política de la primera época, tampoco lo logra desarrollar después de 1886; esta constitución, la de mayor permanencia en la historia colombiana, hija del movimiento Regenerador, significó un recorte sistemático de los derechos individuales, tanto en la Carta como en las prácticas de gobierno; una drástica suspensión del proceso de secularización, iniciado tímidamente desde la independencia y asumido de manera frontal por los gobiernos radicales del medio siglo y una vuelta a la centralización del podery de la nación unitaria $^{\prime \prime 3}$

Las identidades nacional y la ciudadana se sustentaron en torno a la moralidad católica, de tal manera que, los sujetos estaban inscritos a tradiciones culturales, regionales y religiosas; así la sociedad civil y la comunidad católica se concebían como una sola unidad, tal y como lo señala Kalmanovitz, la estructura de la hacienda se reforzó con la presencia de la Iglesia Católica. La esfera pública dejo de ser discutida, ya no se debatía en torno a distintas concepciones del mundo, de distintas morales civiles o religiosas diversas, sino la unidad del buen católico; dejó de estar presente el ciudadano virtuoso e ilustrado

31 Al respecto véase Taylor, Ch. "La política del reconocimiento" en: Argumentos filosóficos. Paidós Barcelona, 1977, y la discusión para este proyecto en: Almanza, T. "Multiculturalismo y su relación con la participación" Avance de investigación. Departamento de filosofía, Uniminuto, Junio de 2005

32 Ibid. pag. 145

33 Ibid. pag. 146 
tolerante y autónomo del primer republicanismo.

Luego, en las reformas constitucionales de los liberales a partir de 1936, ayudaron a remover esta estructura monolítica que mantenía la moral católica, las tradiciones mestizas regionales y el monopolio territorial de las haciendas, que funcionó como mecanismo de exclusión.

La movilización de campesinos minifundistas y de los primeros obreros -como actores nuevos que irrumpieron en la vida política- exigió derechos a la educación, a salarios justos, a la formalización de contratos de trabajo y a la tierra. El liberalismo fomentó estas reformas sociales y económicas, bajo un modelo asistencial interventor, que benefició a estos grupos sociales, pero que, tampoco, se compaginaban con los derechos individuales, especialmente en el juego del mercado libre y la propiedad privada, así como el derecho a la libre expresión.

En 1957 se otorgó el derecho al voto a las mujeres, universalizando así la ciudadanía, pero no como resultado de una movilización ciudadana, como había pasado en los años 30 con los derechos sociales. Parecería que primara en el país el sujeto social y no el sujeto individual y que para los grupos políticos, las reinvidicaciones más importantes sean los derechos sociales a costa de los derechos civiles o políticos.

Por último, la promulgación de la constitución de 1991 estuvo antecedida por una profunda crisis política, la deslegitimación del Estado, la pérdida de identidad de los partidos tradicionales, mientras ascendían los movimientos sociales, comunitarios, urbanos, locales, movimientos de género, etc. cuyas luchas y demandas empujaron la necesidad de convocar la Asamblea Constituyente y enfocaron el perfil comunitario y multicultural de la nueva Carta Política. ${ }^{34}$

A manera de conclusión preliminar, el avance de esta discusión en torno a la cultura, en el marco del multiculturalismo, intenta mostrar que la organización social, el parentesco y su relación con la tierra, son categorías de la antropología cultural que aún tienen vigencia para comprender la configuración de los grupos sociales y culturales del país, especialmente, los grupos mestizos, que se han presentado vinculados a la tenencia y explotación de la tierra y, por esa vía, se han configurado también grupos políticos e, incluso partidos políticos de gran incidencia en la vida de la nación.

La tesis de Maria Teresa Uribe, en cuanto al déficit en la constitución de la ciudadanía moderna, se basa precisamente en la presencia del mestizaje, que no es solamente racial y étnico, sino, una amalgama de culturas, organizaciones sociales y económicas, formas de tenencia y explotación de la tierra.

"En el contexto colombiano y latinoamericano en general, las ciudadanías realmente constituidas siguieron un proceso particular y diferencial de amalgamiento o hibridación de las instituciones liberales de diversa tradición (Republicanas, Democráticas y Liberales), con las comunidades locales, regionales y étnicas, resistentes a los embates por su disolución $\mathrm{n}^{\prime 35}$

Las ciudadanías mestizas y el mestizaje político y cultural puede ser rastreado en los barrios de la ciudad de Bogotá, en los migrantes de todo el país, que han llegado desde hace décadas a la capital, los cuales han reconformado, al menos parcialmente, sus formas de parentesco y de economía y hoy participan de la vida política reproduciendo los círculos de amigos y de patronazgo, desde sus particularidades y necesidades, tanto como grupos comunitarios, vecinales o con iniciativas individuales. 


\section{BIBLIOGRAFÍA}

Bastide, R. Antropología Aplicada, Amorrotu Editores, Buenos Aires, $1^{\circ}$ Edición , 1977

Correa, F. "Regionalización Socio cultural en Colombia". En: Revista Colombiana de Antropología, Vol. XXVII, años 1989-1990, Bogotá, Instituto Colombiano de Antropología.

Díaz Uribe, Eduardo, "El desafío de la participación" en Bogotá Hoy, Consejería de Asuntos Sociales, Alcaldía Mayor de Santafé de Bogotá, Diciembre de 1994

Harris, M. El Desarrollo de la Teoría Antropológica, S. XXI Editores, Madrid, Primera Edición en Español, 1978

Kalmanovitz, S. "Desarrollo capitalista en el campo colombiano"; en: Colombia Hoy, $2^{\circ}$ Edición Siglo XXI Editores, Bogotá, 1978.

Maus, M. "Ensayo sobre los Dones. Razón y Forma del Cambio en las Sociedades Primitivas", en: Sociología y Antropología, Editorial Tecnos, $1^{\circ}$ Edición en Español, 1971, Reimpresión 1979

Sahlins, M. Las Sociedades tribales, Primera Edición en español, Editorial Labor, Barcelona, 1972

Sobrevilla, D. "Idea e Historia de la Filosofía de la Cultura", en: Filosofía de la Cultura. Enciclopedia Iberoamericana de Filosofía, Editorial Trotta, $1^{\circ}$ Edición, Madrid, 1998 Sudarsky John, Densidad y articulación de la sociedad civil en Bogotá. Localidades y sectores 1997 - 2001, Alcaldía Mayor de Bogotá, Colección Cultura democrática, Bogotá, 2003.

Universidad Externado de Colombia, Análisis comparativo de Modelos de Gobierno de Grandes Ciudades. Recomendaciones en torno al modelo de gobierno de Bogotá, D.C. Bogotá, 2000
Taylor, Ch. "La política del reconocimiento" en: Argumentos filosóficos. Paidós Barcelona, 1977, y la discusión para este proyecto en: Almanza, T. "Multiculturalismo y su relación con la participación" Avance de investigación. Departamento de filosofía, UNIMINUTO, Junio de 2005.

Uribe, Ma. T. "Comunidades, ciudadanos y derechos". En: Cortés Rodas, F. Monsalve, Solórzano, Editores. Multiculturalismo. Los derechos de las minorías Culturales. Res Pública. Instituto de Filosofía de la Universidad de Antioquia, D.M. Librero Editor, Murcia, 1999.

Wolf, E. "Relaciones de parentesco, de amistad y de patronazgo en las sociedades complejas". En: Antropología Social de las sociedades complejas. Alianza universidad, Madrid, $1^{\circ}$ Edición en español, 1980. Wolf, E. Los Campesinos, Editorial Labor, Barcelona, 1971

Zambrano P. Fabio. Historia y memoria en la Atenas Suramericana. En Historia Local. Experiencias, métodos y enfoques, La Carreta Editores, Medellín, 2005

Zuleta, E. "Tres culturas familiares en Colombia", E. Revista Número, Edición 30 SeptiembreOctubre-Noviembre de 2001. 